\title{
A CONSTRUÇÃO DA NORMA LINGUÍSTICA NA GRAMÁTICA DO SÉCULO XVIII
}

\author{
Marli Quadros LEITE*
}

- RESUMO: A gramática do Pe. Jerônimo Contador de Argote, Regras da lingua portugueza, espelho da lingua latina, na sua segunda edição (1725), traz um capítulo voltado à variação linguística, que constitui um pequeno tratado de dialetologia, com minucioso estudo dos dialetos regionais e comentários importantes sobre os dialetos sociais, pelos quais se conhece não somente o estágio em que se encontravam os estudos linguísticos da época, como também pormenores sobre a norma do português praticado na época. Essa é uma obra iluminista e tem como objetivo fundamental descrever as regras da língua portuguesa de modo a identificá-la completamente com o latim, de tal maneira que tudo o que, no português, não estivesse de acordo com as regras dessa língua deveria ser posto de lado, e o mestre deveria negar-se a ensinar aos alunos as estruturas desviantes, por considerá-las idiotismos. Essa gramática constrói-se sobre dados linguísticos observados pelo autor na prática da língua e, portanto, não traz exemplos literários. Nosso objetivo é mostrar, com base em princípios e métodos da historiografia linguística, como aspectos da variação linguística foram considerados e registrados nessa gramática e como revelam aspectos da normalização do português.

- PALAVRAS-CHAVE: Uso linguístico. Norma linguística. Variação linguística. Gramática.

\section{Considerações iniciais}

Na história da língua portuguesa, há três gramáticas relevantes de diferentes séculos (XVI, XVIII e XX), no que concerne ao tratamento da variação linguística, todas de suma importância para o estudo da historiografia da gramática e a constituição da norma gramatical. Para falar do assunto, é obrigatória a referência a nossa primeira gramática, a Grammatica da lingoagem portuguesa, de Fernão de Oliveira, publicada em 1536, não somente por ter sido o instrumento que gramatizou o vernáculo, ${ }^{1}$ mas também porque registrou o estado da língua falada por pessoas cultas naquela altura no século XVI, com importantes referências sociolinguísticas. Depois dessa, tem-se de citar a gramática do Pe. Jerônimo Contador de Argote, Regras da lingua portugueza, espelho da lingua latina, na

* USP - Universidade de São Paulo. Faculdade de Filosofia, Letras e Ciências Humanas - Departamento de Letras Clássicas e Vernáculas. São Paulo - SP - Brasil - 05508-900- mqleite@usp.br

1 Vernáculo no sentido da língua nativa, própria dos portugueses. Nessa acepção a palavra é empregada neste trabalho. 
sua segunda edição, de 1725, que traz um capítulo completa e especialmente voltado à variação linguística, com minucioso estudo dos dialetos regionais, e comentários importantes sobre os dialetos sociais, pelos quais se conhece não somente o estágio em que se encontravam os estudos linguísticos da época, como também pormenores sobre o português praticado na época. Além dessas, de séculos mais recuados em relação ao nosso tempo, há a Nova gramática do português contemporâneo, publicada em 1985, de autoria de dois estudiosos da língua portuguesa, ambos filólogos, linguistas e gramáticos, são eles o português Lindley Cintra e o brasileiro Celso Cunha. Essa gramática reflete a preocupação dos autores com o problema da variação linguística e com o estabelecimento de uma norma que pudesse ser tão abrangente quanto possível para permitir a elaboração de um instrumento que pudesse ser consultado por falantes de todas as variedades da língua portuguesa, especialmente por aqueles das variantes europeia, americana e africana.

A diferença entre esses instrumentos são muitas. A primeira decorre naturalmente da época em que foram escritas: a de Fernão de Oliveira é um exemplo de obra renascentista/humanista, voltada para a gramatização do vernáculo, cujo objetivo foi, antes de tudo, enaltecer a língua, ressaltando suas qualidades e eficiência para dizer a ciência e a $\operatorname{arte}^{2}$. A segunda, escrita depois de já passado o momento do registro do vernáculo como língua, é uma obra iluminista e, por isso, tem como objetivo fundamental descrever as regras da língua portuguesa, de modo a identificá-la completamente com o latim, de tal maneira que tudo o que no português não estivesse de acordo com as regras dessa língua, deveria ser posto de lado. O mestre deveria negar-se a ensinar aos alunos as estruturas desviantes, os idiotismos, pois o foco do ensino era a busca pelas regras coincidentes com as do latim. Era a busca pelos universais linguísticos. Essas duas gramáticas constroem-se sobre dados linguísticos observados pelos autores na prática da língua e, portanto, não trazem exemplos literários. ${ }^{3}$ Já na terceira gramática, escrita nos últimos anos do século XX, cuja filiação teórica deve-se ao estruturalismo, toda a elaboração da norma assenta-se sobre exemplos literários, extraídos de textos dos séculos XIX e XX, mas predominantemente deste, e oriundos das três variedades do português, embora de modo não equilibrado, em prejuízo da variedade africana.

Esse artigo inscreve-se no quadro da historiografia linguística (AUROUX, 1992, 1998a, 2007) no âmbito dos estudos da história das ideias linguísticas, já que se volta à análise da constituição do saber linguístico, nesse caso consolidado em

Especialmente, Fernão de Oliveira afirma o português como uma língua diferente do latim, negando, mesmo, a filiação do português a essa língua (LEITE, 2007).

3 Nas Regras, há, contudo, alguns exemplos da linguagem literária quando o autor trata do "dialeto poético", conforme veremos adiante. 
um instrumento linguístico (AUROUX, 1998b), a gramática, que constitui nosso objeto de análise. Para Auroux (2007), o conhecimento, o ato de saber, é uma realidade histórica, marcado pela temporalidade. Por isso, a análise e a descrição de conhecimentos anteriores são fundamentais à interpretação da continuidade dos saberes, embora nem sempre isso se dê por acumulação. O estudo da história do conhecimento é importante para a explicação da relação dos conhecimentos ao longo do tempo, assim como para análise da causalidade existente entre eles. Para que tudo isso seja possível, pode-se considerar o estudo do que Auroux $(1987,2007)$ denomina horizonte de retrospecção, que é o conjunto dos conhecimentos antecedentes ao que se estuda em dado tempo.

\section{O horizonte de retrospecção de Argote}

D. Jerônimo Contador de Argote, português de Colares, nasceu em 1676 e morreu em 1749, em Lisboa, no Convento dos Caetanos. Além de gramático, o padre foi historiador e escreveu, dentre outras, a obra Memórias históricas do arcebispado de Braga (1744), dividida em quatro volumes e dedicada ao rei D. João V. A gramática de Argote, Regras da lingua portugueza, espelho da lingua latina, teve duas edições, tendo sido a primeira, de 1721, publicada sob o pseudônimo Pe. Caetano Maldonado da Gama. A gramática organiza-se em quatro partes: a primeira, com onze capítulos, trata de morfologia; a segunda, com oito capítulos, trata de sintaxe; a terceira, com sete capítulos, trata de sintaxe figurada; e a quarta, acrescentada na edição de 1725, trata da variação linguística. Essa edição, a segunda, é, por isso, diferente da primeira, porque trouxe essa quarta parte com três capítulos, sendo o primeiro "Dos dialectos da lingua portugueza"; o segundo sobre a "Construição da lingua portugueza"; o terceiro sobre "Pratica da regencia da lingua portugueza", acompanhado da análise, apresentada como exercício de uma carta, inédita naquela época, do Padre Antonio Vieira. ${ }^{4}$

Essa foi a primeira sistematização, embora ainda imperfeita, dos dialetos portugueses (continentais, insulares e ultramarinos). ${ }^{5} \mathrm{O}$ comentário sobre 0 assunto é organizado a partir da classificação de três tipos de dialetos: locais ${ }_{\perp}$ de tempo, e de profissão. Ademais, o autor, além de tratar de variedades diatópicas e diacrônicas, trata também da variedade diastrática, embora superficialmente, quando se refere à linguagem popular, à gíria de Lisboa e à linguagem dos ciganos. Os "dialetos de profissão", como denominados pelo gramático são, em verdade, referentes ao estilo (prosa e verso) e não aos dialetos sociais. Antes de Argote,

\footnotetext{
4 Outras novidades da edição são: a revelação do nome do autor e uma dedicatória ao príncipe (que se tornou o rei D. José I).

5 Cf. VASCONCELOS, 1987, p.55.
} 
gramáticos e ortógrafos reconheceram a variação da língua, ${ }^{6}$ mas nenhum havia tocado tão profundamente o assunto.

A gramática beneficiou-se de alguma repercussão na época em que apareceu, mas teve apenas as duas edições, as antes citadas de 1721 e de 1725. Como argumento em favor da importância e reconhecimento da obra, em seu tempo, lembramos que Antonio José dos Reis Lobato (1770, p.XXIX), autor da Arte da Grammatica Portugueza, de 1770, o gramático oficial de Portugal da época do rei D. José I, cuja obra foi recomendada pela reforma pombalina, refere-se às Regras e, embora teça severas críticas a alguns "erros" de Argote (1725), afirma que "[...] não obstante ser huma das melhores, entre as que se tem escrito de linguas vulgares; he diminuta e contem muitas regras falsas".

O texto das Regras de Argote (1725) apresenta-se na forma de diálogo, à moda dos socráticos, ${ }^{8}$ em que "conversam" o Mestre (M.) e o Discípulo (D.), estando o mestre no papel de inquiridor, como Sócrates, para levar o discípulo a refletir e encontrar as respostas sobre os temas gramaticais a respeito dos quais falam.

A gramática de Argote (1725) segue uma tendência universalista já inaugurada, ainda que intuitivamente, na gramaticologia portuguesa, por Fernão de Oliveira e desenvolvida por Amaro de Roboredo, autores que haviam intuído a existência de regras universais nas línguas. Argote (1725), diferentemente dos primeiros, porque muito consciente dessas regras, afirma-se partidário da Grammaire Génerale e Raisonée, de Port Royal, tanto que assim diz na Introdução:

Também advirto que alguns poderão estranhar a explicação, que dou a alguns pontos da Grammatica Portugueza, porém os que forem versados na lição do novo methodo dos Padres da Congregação de Portroial, e da Grammatica discursada do Padre Lami, verão que na explicação da Grammatica Portugueza observo a mesma doutrina, que elles observàrão a respeyto da Latina. (ARGOTE, 1725).

6 Vasconcelos (1987) dá notícia completa de autores que falaram da variação linguística portuguesa antes e depois de Argote (1725), mas aqui transcrevemos apenas as indicações dos autores que o antecederam: Fernão de Oliveira (1536), na Gramática da lingua portuguesa; João de Barros (1540), no Diálogo em louvor de nossa linguagem; Duarte Nunes do Leão (1576 e 1606), na Orthographia da lingua portuguesa e Origem da lingua portugueza; Faria de Souza $(1628,1678,1730)$, em, respectivamente, Europa portuguesa, Epitome de las historias portuguesas e Historia del reyno de Portugal; Ferreira de Vera (1631), na Orthographia ou modo para escrever certo na lingua portuguesa; Bento Pereira, (1666, 1672), nas Regras geraes breves e comprehensivas da melhor orthographia com que se podem evitar erros no escrever da lingua latina, e portugueza e Ars Grammaticæ pro Lingua Lusitana addiscenda Latino Idiomate proponitur[...]; Dom Francisco Manoel de Mello (1721), nos Apologos dialogaes.

7 Reis Lobato (1770) critica também as gramáticas de Fernão de Oliveira (1536), de João de Barros (1540) e do Pe. Bento Pereira (1672).

8 Seguindo a "gramática discursada do padre Lami", como denominou o próprio autor, no prólogo, explicando a sua filiação; assim também Reis Lobato (1770, p.XXIV) se referiu às Regras. 
Na obra, embora a preocupação central seja a confirmação das regras gerais e comuns ao latim e ao português, em várias passagens, Argote (1725) se refere ao uso, para falar de aspectos próprios do português, ou, conforme se observa, de aspectos de variação linguística. Verifica-se que o registro da variação aparece de dois modos na gramática de Argote (1725): 1. nos capítulos em que expõe a doutrina gramatical e nos exemplos em que traz à tona a diversidade; 2 . no capítulo específico em que trata dos dialetos do português.

O exame da variação linguística nessa gramática pode ser feito a partir de dois pontos de vista: o da relação das regras do português em contraste com as do latim, que produz um tipo de variação que consideramos exógena; e o da variação interna ao português, que consideramos endógena, já que o autor toma como parâmetro para análise da diversidade linguística um dos dialetos, o da Estremadura, especialmente o praticado por pessoas cultas, em relação aos dialetos de outras províncias, de pessoas cultas, ou não.

\section{A variação exógena: regras do português em contraste com as do latim}

Retomamos, para melhor explorá-los, os títulos " Dos idiotismos, Das figuras de dicção" " "Das palavras enclíticas" por entender que há aí registros valiosos sobre o uso e a variação na língua portuguesa. Considera-se que, nesse caso, a variação como exógena porque se percebe que o autor entendeu como "diferentes" todos os fenômenos em que as regras do português são divergentes daquelas do latim.

No capítulo V, à pergunta do mestre sobre o que é idiotismo, o discípulo responde:

\footnotetext{
M. E neste Capitulo, que entendeis pela palavra Idiotismo?

D. Entendo todos os modos, e termos de fallar a lingua Portugueza, que não tem conveniencia, ou semelhança com a Grammatica Latina, ainda que os taes modos de fallar da lingua Portugueza se achem na Grammatica de outras linguas vulgares, assim como na Castelhana, Italiana, \&c. (ARGOTE, 1725, p.258).
}

É pela descrição dos idiotismos que se conhecem, então, fenômenos típicos da língua portuguesa. Esse capítulo mostra claramente que um dos focos de preocupação do gramático é a variação da língua portuguesa em relação ao latim, tanto que a explicação dos fenômenos tipicamente portugueses parece escapar da capacidade do autor para formular regras, já que, até então, a atenção maior dos gramáticos recaía sobre as regras do latim, língua sobejamente gramatizada e explorada, o que não se podia afirmar sobre a língua portuguesa até então; por isso, quando o Mestre indaga ao Discípulo acerca das regras dos idiotismos, esse não tem outra saída a não ser dizer que não se deve ensinar a 
gramática "bárbara" aos alunos, como se poderá verificar a seguir pela leitura dos exemplos.

Os idiotismos apresentados dizem respeito a: 1. uso dos artigos; 2. declinações dos nomes e terminações dos casos; 3. ausência de plural dos pronomes demonstrativos (isto, isso, aquilo) e adjetivo [indefinido] tudo; 4. emprego de voz, tempos e modos verbais; 5. uso de advérbios, preposições e conjunções; 6. emprego da concordância; emprego da regência; 7. uso de metáforas.

O capítulo VI, "Das figuras de Dicção", traz as regras e os exemplos portugueses sobre os fenômenos de adição, subtração e comutação, mas, como se observa na fala do próprio Discípulo, não há ênfase sobre isso na obra, embora para todos os tipos de metaplasmos existam exemplos. Evidentemente esse é um tema importante para o conhecimento da variação linguística, porque é o uso que modifica as palavras por meio dos referidos processos de alteração fonética das palavras.

Para que a matéria fique mais bem explicada, apresentamos, a seguir, um quadro em que se vê resumida e estruturada a lição do autor sobre os metaplasmos:

\begin{tabular}{|c|c|c|c|c|}
\hline $\begin{array}{c}\text { Figura } \\
\text { [Metaplasmo] }\end{array}$ & $\begin{array}{c}\text { Posição na palavra/ } \\
\text { Classificação }\end{array}$ & $\begin{array}{l}\text { Conhecimento } \\
\text { caso a caso. }\end{array}$ & $\begin{array}{l}\text { Frequência de } \\
\text { uso na LP }\end{array}$ & Exemplos \\
\hline $\begin{array}{l}\text { Addiçaõ - quando } \\
\text { na palavra se accres- } \\
\text { centa alguma letra, } \\
\text { que segundo as re- } \\
\text { gras commuas naõ } \\
\text { devia ter. }\end{array}$ & $\begin{array}{l}\text { Principio - prothèse } \\
\text { Meyo - epenthese } \\
\text { Fim - paragoge }\end{array}$ & $\begin{array}{l}\text { Pelo uso. } \\
\text { Pelo uso. } \\
\text { Pelo uso. }\end{array}$ & $\begin{array}{l}\text { 1. Naõ muyto usada. } \\
\text { Naõ muyto usada. } \\
\text { Naõ }\end{array}$ & $\begin{array}{l}\text { Sombrar por Assombrar; } \\
\text { Quera por queyra \&c. } \\
\text { Quis. }\end{array}$ \\
\hline $\begin{array}{l}\text { Subtracçaõ - quan- } \\
\text { do na palavra se tira } \\
\text { alguma letra, ou le- } \\
\text { tras, que segundo } \\
\text { as regras commuas } \\
\text { devia ter. }\end{array}$ & $\begin{array}{l}\text { Principio - apherese. } \\
\text { Meyo - syncope. } \\
\text { Fim - apocope. }\end{array}$ & $\begin{array}{l}\text { Pelo uso. } \\
\text { Pelo uso. } \\
\text { Pelo uso. }\end{array}$ & $\begin{array}{l}\text { Naõ. } \\
\text { Sim. } \\
\text { Naõ. }\end{array}$ & $\begin{array}{l}\text { Pollonia por Appolonia; } \\
\text { Amares por amardes; } \\
\text { heis por haveis; } \\
\text { Dirme-há por dizerme- } \\
\text { há \&c. } \\
\text { Quer por quere. }\end{array}$ \\
\hline $\begin{array}{l}\text { Comutaçaõ - na pa- } \\
\text { lavra se muda huma, } \\
\text { ou muytas letras em } \\
\text { outra, ou outras, con- } \\
\text { tra as regras commu- } \\
\text { as. }\end{array}$ & - & Pelo uso. & Sim. & $\begin{array}{l}\text { Digo, diga, perco, perca } \\
\text { minto, minta de dizer, } \\
\text { pedir, mentir; lede de ler; } \\
\text { peço de pedir; despeço } \\
\text { de despedir. Prisão de } \\
\text { prender. No, na, nos nas } \\
\text { de em + o, a, os, as; pelo, } \\
\text { pela de por + o, a, os, as. } \\
\text { Cento de cem; Santo de } \\
\text { São. Grão de grande, \&c. }\end{array}$ \\
\hline
\end{tabular}




\begin{tabular}{|c|c|l|l|l|}
\hline $\begin{array}{c}\text { Figura } \\
\text { [Metaplasmo] }\end{array}$ & $\begin{array}{c}\text { Posição na palavra/ } \\
\text { Classificação }\end{array}$ & $\begin{array}{c}\text { Conhecimento } \\
\text { caso a caso. }\end{array}$ & $\begin{array}{c}\text { Frequência de } \\
\text { uso na LP }\end{array}$ & \multicolumn{1}{|c|}{ Exemplos } \\
\hline $\begin{array}{l}\text { Apostrophe - quan- } \\
\text { do a palavra perde } \\
\text { a ultima vogal para } \\
\text { hir continuando cõ a } \\
\text { palavra, que lhe vay } \\
\text { diante, e formarem } \\
\text { ambas huma só pa- } \\
\text { lavra.. }\end{array}$ & - & Pelo uso. & Sim. & $\begin{array}{c}\text { Antontem de ante e on- } \\
\text { tem; Pedralvares de Pe- } \\
\text { dro Alvares; Marianna de } \\
\text { Maria Anna; Dissemo de }\end{array}$ \\
\hline
\end{tabular}

Quadro 1 - Figuras de dicçaõ ${ }^{9}$

Fonte: Autoria própria.

O processo denominado pelo autor apóstrofe traduz a tendência da fonética do português europeu de elidir ou reduzir as sílabas pré ou pós tônicas. Sobre o registro gráfico das palavras resultantes de tal processo, o autor esclarece que ficam as palavras que perdem sílabas, ou parte delas, juntas em uma palavra só, porque o português, àquela altura, não possuía o diacrítico, o apóstrofo, como outras línguas, para que se pudesse registrar a perda de sons, por exemplo, Pedr'Alvares.

O capítulo VII, "Das palavras Encliticas", é importante para a historiografia gramatical por ser a primeira sistematização, para o português, do fenômeno da ênclise e, também, porque registra o fato de a posição da partícula enclítica ser variável para o português europeu, até o século XVIII. No comentário sobre a ênclise, evidentemente, observa-se a tendência da época a respeito da próclise e se verifica que ambos os fenômenos, desde a origem, foram entendidos e explicados pela entoação.

Depois da explicação sobre o conceito da "dicção enclitica", isto é, da perda de força tonal da partícula que se põe em ênclise, o mestre pergunta, e o discípulo responde:

\section{E que cousa he tom?}

D. He hum certo geyto, ou diversidade de som, com que pronunciamos a mesma palavra, ou particula.

\section{Dizey exemplo.}

D. Dizme nesta palavra a particula Me se pronuncia com algum geyto, ou diversidade, do que quando pomos a particula $M e$, antes do Verbo Diz, e pronunciamos Me diz. (ARGOTE, 1725, p.287, grifo nosso).

9 Mantém-se, nas transcrições, a ortografia original da obra. 
Importante, também, é que o gramático restringiu o conceito de ênclise ao problema da colocação pronominal, como se pode ver no seguinte trecho:

M. E quaes saõ as particulas, ou dicçoens Encliticas na lingua Portugueza?

D. Saõ estas $M e, T e, S e$, Lhe, Nós, Vós, Lhes, e a meu ver tambem os relativos $O, O S, A, A S$.

M. E quaes saõ as regras dos Encliticos?

D. Saõ estas. Todas as vezes que estas particulas ou pronomes Me, Te, Se, Lhe, Nós, Vós, Lhes, se poem logo depois do Verbo, se fazem Encliticas. Isto he mudaõ o seu tom. (ARGOTE, 1725, p.287, grifo nosso).

Essa passagem não deixa dúvidas de que, para o autor, o conceito da ênclise não se faz primeiro pela posição da partícula depois do verbo, mas, ao contrário, pela mudança de tom, de forte para fraco, da partícula que se põe depois do verbo, e é pelo enfraquecimento do tom que ela se faz enclítica. O fenômeno é fonético e tem consequência sintática, como foi, séculos depois, retomado por Ali (1908) para explicar a preferência pela próclise na prática do português do Brasil. Esse tema, contudo, por não ter sido bem compreendido desde a origem, foi motivo de polêmicas linguísticas no Brasil, nos séculos XIX e XX (até meados), e configurou a identidade do português praticado pelos brasileiros. Hoje uma gramática de referência, como a de Cunha e Cintra (1985), traz um subcapítulo intitulado "A colocação dos pronomes átonos no Brasil".

O conceito da próclise existe, embora o fenômeno não seja como tal denominado nas Regras, quando o autor trata dos casos em que os pronomes (tônicos ou átonos) são postos antes do verbo. A explicação para isso é a seguinte:

M. E quando estas particulas, ou pronomes se poem antes do Verbo, saõ Encliticas?

D. Naõ.

M. Dizey exemplo.

D. Pedro me he suspeyto, onde a particula Me, naõ he Enclitica, porque està antes do Verbo.

M. E estes pronomes, ou particulas podem-se por antes, ou depois do Verbo?

D. Communmente ou se pòdem pòr antes, ou depois.

M. Dizey exemplo.

D. Tu dàslhe paõ, ou Tu lhe dàs paõ, onde a particula Lhe em huma Oração está depois do Verbo Das, em outra está antes 
M. E quando saõ Encliticos os relativos $O, O s, A, A s ?$

D. Quando se ajuntaõ aos pronomes $M e, T e$, \&c. que vem logo depois dos Verbos.

M. Dizey exemplo.

D. Deylhos, onde o relativo Os está Enclitico, porque se ajunta ao pronome Lhe vindo depois do Verbo Dey. (ARGOTE, 1725, p.289, grifo nosso).

Para reforçar a ideia de que a colocação pronominal do português europeu no século XVIII não sofria as restrições que vieram a vigorar depois, trazemos à luz duas outras gramáticas: primeiro, a gramática oficial, porque recomendada pelo alvará pombalino, a Arte de Grammatica da Lingua Portugueza, de António José dos Reis Lobato, publicada em 1770; e, segundo, a gramática de Pedro José da Fonseca, Rudimentos da Grammatica Portugueza, Cómmodos á instrucção da Mocidade, e confirmados com selectos exemplos de bons Autores, de 1799, uma das primeiras gramáticas portuguesas construídas com exemplificação literária. ${ }^{10}$

Na Arte, não há, propriamente, referências à colocação dos pronomes, mas veem-se casos de colocação embutidos, lateralmente, no livro IV, "Das Figuras da Dicção", que trata dos metaplasmos, "Synalefa, Aferese, Syncope, Apocope, Antithese, Prothese". Assim, diz o autor:

Usa-se Synalefa nos Pronomes $M e, T e$, Lhe, quando se lhes seguem $O$, oS, a, as; porque então perdem a vogal final e, e se ajuntão com a vogal da palavra seguinte, pronunciando-se ambas, como se fosse huma só; porque dizemos: Mo, Mos, Ma, Mas, To, Tos, Ta, Tas, Lho, Lhos, Lha, Lhas, em lugar de Me-os, Me-a, Me-as, Te-o, Te-os, Te-a, Te-as, Lhe-o, Lhe-os, Lhe-a, Lhe-as, como v.g. quando dizemos: Entregárão-mo, Derão-ta, Affirmárão-Iho, em lugar de Entregárão-me-o, Derão-te-a, Affirmárãolhe-o. (LOBATO, 1770, p.223).

Ao tratar da Syncope, todavia, Lobato (1770) sugere outra possibilidade de uso das formas de futuro, em que o pronome aparece intercalado entre o verbo principal e a forma sincopada do passado do verbo haver, quando comenta a figura da sinalefa, acima apresentada. Nesse caso, este é o texto:

Usa-se da figura da Syncope em todas as pessoas, assim do singular, como do plural do preterito imperfeito do indicativo do verbo Haver, quando se pospõe á voz infinita do presente de qualquer verbo, dividindoos pela figura Tmesis alguma das seguintes palavras: Me, Te, Lhe, Nós, Vós, Lhes, O, Os, A, As; porque dizemos Ama-lo-hia, Ama-lo-hias,

10 Há outra gramática, também de 1799, de Pedro José de Figueiredo, que traz exemplos literários. 
Já a gramática de Pedro José da Fonseca (1799) traz um parágrafo (§ IV) do capítulo sobre sintaxe dedicado à colocação pronominal, cujo título é $D a$ Construcção do verbo com o pronome. E nesse caso, assim como na gramática de Argote (1725), a regra de colocação permite a posição proclítica ou enclítica, sem restrições. Assim, diz o autor:

Os pronomes pessoaes, e demonstrativos se ajuntão aos verbos, quando a significação destes recahe sobre os ditos pronomes, pondo-se, ou antes, ou depois dos mesmos verbos, com aquellas terminações, que são proprias de cada hum delles.

Pelo que tanto póde dizer-se: me louvas, te estimo, se vai, o, ou a lisonjeo, os ou as engrandecem, se vingão; como: louvas-me, estimo-te, vai-se, lisonjea-o, ou lisonjea-a, engrandecem-nos, ou engrandecem-nas, vingão-se. (FONSECA, 1799, p.242-243).

Vê-se, assim, que as regras de colocação pronominal, com predomínio para a ênclise, não foram gramatizadas no século XVIII. A gramatização é processo contínuo que acompanha a variação e a mudança da língua (AUROUX, 1992).

\title{
A variação endógena: os demais dialetos versus o da Estremadura
}

A quarta parte das Regras é completamente voltada para a questão do uso linguístico e sua variação. São dois capítulos que a formam: I. Dos dialectos da lingua Portugueza; e II. Da construição da lingua Portugueza. Ambos voltam-se para as diferenças que o autor observou internamente na língua portuguesa, no que diz respeito a diferenças regionais, sociais, temporais, e de profissão. Nesse último caso, no que tange à diferença de estilo, prosa e verso. Passaremos, pois, a explorar essas diferenças endógenas do português.

Primeiro, observa-se a posição inequívoca do autor quanto à conceituação de dialeto, como um fenômeno de variação interna da língua:

\author{
Mestre. Que quer dizer Dialecto? \\ D. Quer dizer modo de falar. \\ M. Que cousa he Dialecto?
}

D. He o modo diverso de falar a mesma lingua.

M. Dizey exemplo 
D. O modo, com que falla a lingua Portugueza nas terras v.g. da Beyra, he diverso do que se falla a mesma lingua Portugueza em Lisboa porque em huma parte se usa de humas palavras, e pronuncia, e em outra parte se usa de outras palavras, e outra pronuncia, naõ em todas as palavras, mas em algumas. Esta diversidade pois de fallar, que observa a gente da mesma lingua, he que se chama Dialecto. (ARGOTE, 1725, p.291-292, grifo nosso).

Depois, a clareza quanto à classificação dos dialetos, e, também, a descrição de cada um deles:

M. E quantas castas há de Dialectos?

D. Muytas, mas as principaes saõ tres.

M. Quaes saõ?

D. Dialectos locaes, e Dialectos de tempo, e Dialectos de profissaõ. (ARGOTE, 1725, p.292, grifo nosso).

O estudo recai sobre fatos de fonética, morfologia e léxico, que o autor usa para comparar as diferenças dos vários dialetos relativamente ao padrão da Estremadura.

Os dialetos locais são aqueles referentes às variações regionais, e são citados cinco que o autor julga de maior importância: o da Estremadura, tomado como parâmetro para toda a comparação; o do Entre Douro e Minho, o da Beyra e, finalmente, o do Algarve. O dialeto do Alentejo não é citado entre os considerados principais porque, segundo o autor entendeu, pouco diferia daquele da Estremadura. Outros dialetos rapidamente citados são os do norte de Portugal, de Trás os Montes e Minho, ditos "muyto barbaros, e quase que se naõ pódem chamar Portuguez, mas só os usa a gente rustica da quelles lugares." (ARGOTE, 1725, p.293). E aqui se observa uma referência à diferença social da língua, já que essa população do norte é considerada rústica em face de outra certamente polida. Há, também, referência aos dialetos ultramarinos (Índia e Brasil).

Os dialetos de tempo são divididos em três classes: antiquíssimo, antigo e moderno. $\mathrm{O}$ autor, contudo, não chega a fornecer exemplos desses dialetos.

Os dialetos de profissão são relativos às diferenças de uso da língua em prosa (literária ou familiar) e da língua poética, praticada em verso.

Embora os dialetos sociais não tenham sido citados entre as três classes declinadas explicitamente, o autor não deixou de tratar desse tipo de variação, ao referir-se à linguagem popular em geral, à linguagem dos ciganos e à gíria lisboeta.

O quadro apresentado a seguir mostra os pontos principais da teoria de Argote (1725): 


\begin{tabular}{|c|c|c|}
\hline Local & Natureza da variação & Exemplos \\
\hline $\begin{array}{l}\text { Provincia da Estremadura } \\
\text { (padrão) }\end{array}$ & $\begin{array}{l}\text { 1. Diferença fonética. } \\
\text { a. Troca do } V \text { pelo } B \text {. } \\
\text { b. Troca de -ão por -om. } \\
\text { 2. Diferença lexical } \\
\text { 3. Diferença morfológica: } \\
\text { a. gênero dos nomes. } \\
\text { b. conjugação verbal. }\end{array}$ & $\begin{array}{ll}\text { a. } & \text { Vinho } \rightarrow \text { Binho; } \\
& \text { Vento } \rightarrow \text { Bento. } \\
\text { b. } & \text { Naõ } \rightarrow \text { Nom; } \\
& \text { Paõ } \rightarrow \text { Pom. } \\
& \\
\text { a. } & \text { Viração } \rightarrow \text { Maré; } \\
& \text { Alameda } \rightarrow \text { Devesa. } \\
& \\
\text { a. } & \text { O fim } \rightarrow \text { A fim. } \\
& \text { A febre } \rightarrow \text { O febre } \\
\text { b. } & \text { Eu estive } \rightarrow \text { eu esteve. } \\
& \text { Eu fiz } \rightarrow \text { eu fez. }\end{array}$ \\
\hline Provincia da Beyra & $\begin{array}{l}\text { 1. Diferença fonética. } \\
\text { a. Troca de -ou por -oi. } \\
\text { b. Epêntese de -i em palavras } \\
\text { iniciadas por A. } \\
\text { 2. Diferença lexical }\end{array}$ & $\begin{array}{l}\text { a. Ouvir } \rightarrow \text { Oyvir, } \\
\text { Couves } \rightarrow \text { Coyves. } \\
\text { * O autor observa que esse uso } \\
\text { se espalhou pela Estremadura, } \\
\text { pois lá algu mas palavras } \\
\text { apresentam a troca do ditongo: } \\
\text { couro } \rightarrow \text { coyro; mouro } \rightarrow \text { moyro; } \\
\text { touro } \rightarrow \text { toyro. } \\
\text { b. A agua } \rightarrow \text { Aiagua; } \\
\text { A alma } \rightarrow \text { Aialma. } \\
\text { Canteyros } \rightarrow \text { Leyras; } \\
\text { Vagados } \rightarrow \text { Oyras. } \\
\text { Rapazes } \rightarrow \text { Cachopos. } \\
\text { Moças } \rightarrow \text { Cachopas. }\end{array}$ \\
\hline $\begin{array}{l}\text { Provincia de Tras os } \\
\text { Montes }\end{array}$ & $\begin{array}{l}\text { 1. Diferença fonética. } \\
\text { 2. Diferença lexical. }\end{array}$ & $\begin{array}{l}\text { "Differe na pronuncia, e } \\
\text { nas palavras que condizem } \\
\text { muyto com as da Beyra, e } \\
\text { Entre Douro e Minho." }\end{array}$ \\
\hline Provincia de Algarve & $\begin{array}{l}\text { 1. Diferença fonética. } \\
\text { a. Troca do }-e \text { pelo }-i \text {. } \\
\text { b. Troca do -i pelo -e. }\end{array}$ & $\begin{array}{l}\text { a. Pedaço } \rightarrow \text { Pidaço. } \\
\text { b. Dizer } \rightarrow \text { Dezer. }\end{array}$ \\
\hline
\end{tabular}




\begin{tabular}{|l|l|l|}
\hline \multicolumn{1}{|c|}{ Local } & \multicolumn{1}{|c|}{ Natureza da variação } & \multicolumn{1}{|c|}{ Exemplos } \\
\hline $\begin{array}{l}\text { Provincia do Alentejo } \\
\text { (dialeto semelhante ao da } \\
\text { Estremadura, com alguns } \\
\text { defeitos da pronúncia do } \\
\text { Algarve) }\end{array}$ & $\begin{array}{l}\text { 1. Diferença lexical. } \\
\text { Concertar } \rightarrow \text { Amanhar; } \\
\text { Casaes } \rightarrow \text { Montes. }\end{array}$ \\
\hline $\begin{array}{l}\text { India e Brazil \& c. - } \\
\text { dialectos ultramarinos e } \\
\text { conquistas de Portugal. }\end{array}$ & $\begin{array}{l}\text { 1. Diferença lexical: } \\
\text { a. presença de termos de bárbaras. } \\
\text { b. presença de vocábulos do } \\
\text { português antigo. }\end{array}$ & - \\
\hline
\end{tabular}

Quadro 2 - Dialectos locaes

Fonte: Autoria própria.

\begin{tabular}{|c|c|c|}
\hline Classificação & Localização temporal & Observação \\
\hline Antiquíssimo & $\begin{array}{l}\text { Usado até o tempo de El } \\
\text { Rey D. Diniz, o sexto de } \\
\text { Portugal. } \\
\text { Aproximadamente de } 1139 \\
\text { a } 1185 .\end{array}$ & $\begin{array}{l}\text { Existente nos livros } \\
\text { de doações antigas. } \\
\text { Semelhante ao atual [da } \\
\text { época] dialeto do Minho, } \\
\text { Beira e Trás os Montes. }\end{array}$ \\
\hline Antigo & $\begin{array}{l}\text { Usado até quase a perda } \\
\text { de El Rey D. Sebastião. } \\
\text { Aproximadamente de } 1185 \\
\text { a } 1578 .\end{array}$ & Idem. \\
\hline Moderno & $\begin{array}{l}\text { Usado desde a perda de } \\
\text { D. Sebastião até a época } \\
\text { contemporânea ao autor. } \\
\text { Aproximadamente de } 1578 \\
\text { a } 1725 \text {. }\end{array}$ & \\
\hline
\end{tabular}

Quadro 3 - Dialetos de tempo

Fonte: Autoria própria.

\begin{tabular}{|l|l|l|}
\hline \multicolumn{1}{|c|}{ Tipos } & \multicolumn{1}{|c|}{ Classificação } & \multicolumn{1}{c|}{ Observações } \\
\hline $\begin{array}{l}\text { Prosaico } \\
\text { (qualquer linguagem em prosa) }\end{array}$ & $\begin{array}{l}\text { 1. Linguagem familiar. } \\
\text { 2. Linguagem literária. }\end{array}$ & $\begin{array}{l}\text { Conserva a ordem natural } \\
\text { das palavras na frase. }\end{array}$ \\
\hline Poético & Realização em verso. & $\begin{array}{l}\text { Inverte a ordem natural } \\
\text { das palavras. }\end{array}$ \\
\hline
\end{tabular}

Quadro 4 - Dialetos de profissão

Fonte: Autoria própria. 
Para melhor esclarecer a teoria do autor quanto aos dialetos prosaico e poético, é importante apresentar um trecho da conversa entre o mestre e o discípulo. Como é fácil observar, Argote (1725) não admite o uso, no dialeto prosaico, na prosa, de inversão da ordem tida como natural, pelo que se percebe a partir de suas considerações das possibilidades de inversão da ordem dos elementos na frase. As inversões são próprias e aceitáveis apenas no dialeto poético, na poesia, e é assim que o problema é explicado:

\section{E em que differe o Dialecto Poetico do Prosaico?}

D. Differe nas palavras, e na ordem das palavras.

M. Porque differe nas palavras?

D. Porque ao que no Dialecto Prosaico chama Throno, o Poetico muytas vezes chama Solio, ao Sol chama Febo, ao Chegar diz Appropinquar. Ao Ceo chama Polo, \&c.

M. E porque differe na ordem das palavras?

D. Porque o Dialecto da prosa sempre conserva a ordem natural das palavras, segundo deyxamos dito na Syntaxe. Porém o Dialecto Poetico muytas vezes não conserva a tal ordem, antes usa da figura Hyperbaton, e Synchisis, que explicamos no Capitulo quarto da Syntaxe figurada.

M. Dizey exemplo.

D. O Sileno buscava

Daquellas que a serra deu bacantes

Ja que Ninfas as nega ser errantes

O Hombro sem aljava.

Nestes versos a palavra Sileno significa o Guarda, Bacantes significa Loucas, Ninfas significa Mulheres, Errantes significa Vagabundas, e a ordēm está toda cõfusa, e ordenada no Dialecto familiar devia ser assim- Buscava ao guarda daquellas mulheres loucas, que vinhaõ pela serra, pois o não trazerem aljava no hombro mostrava não serem mulheres vagabundas. Onde se vè que he muyto diversa a ordem, que as palavras tem no Dialecto Poetico, e no de prosa. (ARGOTE, 1725, p.298).

Embora não arrolado, o dialeto social tem espaço na teoria de Argote, tanto que há duas classificações: o Dialecto rustico, mao e o Dialecto verdadeyro. Assim se pode resumir o que o autor diz sobre esse assunto: 


\begin{tabular}{|c|c|c|}
\hline Tipos & Conceito & $\begin{array}{l}\text { Exemplos: Dialecto } \\
\text { verdadeyro x Dialecto rústico }\end{array}$ \\
\hline Verdadeyro & [Usado pelas pessoas educadas] & $\begin{array}{l}\text { Por certo } \rightarrow \text { bofé } \\
\text { Tostoens } \rightarrow \text { tostaens }\end{array}$ \\
\hline Rustico, mao, viciado & $\begin{array}{l}\text { Usado pela gente ignorante, } \\
\text { rústica e incivil. }\end{array}$ & $\begin{array}{l}\text { Grão } \rightarrow \text { grães } \\
\text { Vizita } \rightarrow \text { vigita } \\
\text { Vizitar } \rightarrow \text { vigitar } \\
\text { Fizera } \rightarrow \text { figera } \\
\text { Eu truxe } \rightarrow \text { eu trouve } \\
\text { Ouvido } \rightarrow \text { ouvisto } \\
\text { Atreverse } \rightarrow \text { estreverse } \\
\text { Flores } \rightarrow \text { froles }\end{array}$ \\
\hline Giria & $\begin{array}{l}\text { Usado pelos "homens de } \\
\text { ganhar"; linguagem de grupo. }\end{array}$ & \\
\hline Ciganos & $\begin{array}{l}\text { Espécie de gíria usada pelos } \\
\text { ciganos; linguagem de grupo. }\end{array}$ & \\
\hline
\end{tabular}

Quadro 5 - [Dialetos sociais]

Fonte: Autoria própria.

No segundo capítulo dessa quarta parte, Argote (1725) trata também de variação quando explica seu conceito de "construição". O termo "construição", em acepção diferente da que já se fizera dele, por exemplo, da que Prisciano ${ }^{11}$ lhe dera, é empregado por Argote (1725) no contexto da tradução, ou da versão, no sentido da operação de organizar as palavras da língua portuguesa na frase, na "ordem natural", para o que se deve fazer dois movimentos: i) o da troca de palavras de um texto para o outro, quer se trate da tradução de uma língua para outra quer se trate simplesmente da versão de um gênero ou estilo discursivo para outro; ii) o da ordenação das palavras na frase, quer a tradução seja de uma língua para outra quer seja de um dialeto para outro, ou mesmo de um estilo para outro. A explicação e a exemplificação do fenômeno da construição são dadas a partir da transposição de versos, ou estrofes, para trechos em prosa.

A construição é explicada por meio de nove regras que, em resumo, têm o objetivo de orientar a ação de quem vai traduzir um texto a fim de deixar as

11 Gramático latino, de Constantinopla, do começo do século VI d.C., que escreveu a obra Institutionum grammaticarum libri XVIII, escrita entre 526-527. Essa obra pode ser consultada pela edição de Keil (1961). 
palavras ordenadas no modo considerado normal da língua alvo. O início do diálogo entre o mestre e o discípulo, sobre esse assunto, dá-se nos seguintes termos:

M. E como se sabe trocar as palavras de huma lingua nas palavras de outra lingua, ou palavras de hum Dialecto nas de outro Dialecto?

D. Isso se sabe pelos Vocabularios.

M. E como se sabe mudar as palavras da ordem confusa para a ordem natural?

D. Sabe-se pelas regras da Construição.

M. Que cousa saõ as regras da Construição?

D. Saõ as regras que ensinaõ a pòr em huma lingua na ordem natural as significaçõens daquillo, que em outra lingua, ou Dialecto estava na ordem perturbada, e confusa.

M. Dizey essas regras.

D. Primeyra regra. Na Construição a primeyra palavra, que e deve buscar na Oração confusa, he o nome, que faz na Oração, e serve ao verbo de nominativo ou claro, ou occulto, e esta se deve pòr primetro na Oração feyta na ordem natural, e Dialecto da prosa.

M. Dizey exemplo.

D. Insuflava nos mares furiozo.

Com rapida procella o Austro iniquo.

Nesta Oração, q està feyta no Dialecto Poetico cõfuso, para lhe desfazer a cõnfusaõ, e a pòr na ordē natural do Dialecto Prosaico, deve-se buscar quem he o nome, que faz na Oração e serve de nominativo ao Verbo Insuflava, que significa soprar, e acharemos que he o nome Austro, que significa o Vento Sul, porque esse nome he o que serve de pessoa ao verbo Insuflava; e assim construiremos primeyro, e poremos na Oração natural a palavra Austro, dizendo o Vento Sul, \&c. (ARGOTE, 1725, p.303-304).

A citação das demais regras não cabe aqui, mas, pelo que foi apresentado, é possível verificar a importância dessa teorização para a compreensão da diferença de uso e norma da língua portuguesa do século XVIII. Nessa época, consideravase não somente a variação entre as modalidades da língua (falada e escrita), mas também aquela existente entre os gêneros de uma mesma modalidade (prosaico e poético). 


\section{Considerações finais}

Como intentamos desvelar, devido a sua orientação teórica, o texto de Argote (1725) traz com precisão e minúcia, para a época em que foi escrito, fatos de variação linguística que mostram dados do uso e da norma da língua portuguesa. Como afirmou Vasconcelos (1987), Argote foi o primeiro a desenhar o quadro da dialetologia portuguesa e, como observou também esse autor, o gramático não procedeu como outros (especialmente ortógrafos e puristas) que, antes dele, fizeram referências à diversidade linguística, sempre considerando os dialetos populares como corrompidos e dignos da censura. Argote (1725) organizou, mesmo com restrições à diversidade dialetal, observáveis pela qualificação feita especialmente à gente da Região Norte não praticante do dialeto verdadeyro ("ignorante", "rústica", "incivil"), o quadro da variação linguística, classificando os diversos falares, a partir de critérios, alguns até hoje válidos. O gramático português não fez uma obra de "descrição linguística" no sentido moderno, uma gramática descritiva, tal como é hoje denominada, mesmo assim contribuiu para o reconhecimento de que o português não era uma língua homogênea, como é comum ver-se em obras gramaticais de todas as épocas. O capítulo IV, pois, é fonte para a leitura da heterogeneidade da língua portuguesa do século XVIII.

A análise da obra de Argote (1725), pelo prisma do horizonte de retrospecção, exige que se vá além do que se fez neste artigo, pois exige que se examine o tratamento dado pelos gregos à questão da variação linguística, pois, como alertou Vasconcelos (1987), a fonte de Argote (1725) para a elaboração da teoria dialetológica que compõe sua obra foi grega. Um estudo comparativo das Regras com as obras gregas que tratam da língua grega em oposição às consideradas bárbaras (todas as não gregas), todavia, é uma etapa ainda a ser cumprida e que não deve ser negligenciada, pois essa conexão constitui fato relevante para que se complete o conhecimento dessa fase da elaboração da teoria linguística portuguesa.

Finalmente, pode-se dizer que o exame da obra de Argote (1725), pela análise de seu horizonte de retrospecção, é relevante para a compreensão da construção do saber linguístico sobre o português. Enfatiza-se, ainda uma vez, que na obra aqui examinada encontram-se registrados fatos de uso e norma da língua portuguesa, revelados especialmente nos comentários sobre os idiotismos, pelos quais também se gramatizou a língua portuguesa.

LEITE, M. Q.The construction of linguistic norm in an $18^{\text {th }}$ century Portuguese grammar. Alfa, Araraquara, v.55, n.2, p.665-684, 2011. 
- ABSTRACT: Published in 1725, the second edition of Jerônimo Contador de Argote's "Regras da lingua portuguesa: espelho da língua latina" [Rules of the Portuguese language: mirror of Latin] contains a chapter dealing specifically and thoroughly with languistic variation. Argote's grammar is indeed important for he examines both regional and social dialects of Portuguese thereby enabling researchers to ascertain the state of the art of language studies as well as the prevailing norm of the language in Portugal in the $18^{\text {th }}$ century. Truly a masterpiece of the Enlightenment, the goal of the author was to describe the structure of Portuguese and compare it with Latin. Syntactic rules that diverged from those in Latin were to be ignored. Argote (1725) recommended that instructors of Portuguese in schools refrained from teaching syntactic structures deviant from the Latin norm and contended also that such practice would be unsound. The data of this grammar text is based on the author's observation of the language in everyday practice and, therefore, no literary examples are provided. Our aim in this study, based on the principles and methods of linguistic historiography, is to illustrate (i) how the aspects of linguistic variation were accounted for, (ii) how they were recorded in the text, and (iii) what they reveal about the attempt to identify and establish a norm for the Portuguese language at that moment in history.

- KEYWORDS: Linguistic usage. Linguistic norm. Linguistic variation. Grammar book.

\section{REFERÊNCIAS}

ALI, S. Dificuldades da língua portuguesa. Rio de Janeiro: Acadêmica, 1908.

ARGOTE, J. C. de. Regras da lingua portugueza, espelho da lingua latina: ou disposiçaõ para facilitar o ensino da lingua latina pelas regras da portugueza. Lisboa: Officina da Musica, 1725.

AUROUX, S. La question de l'origine des langues suivi de L'historicité des sciences. Paris: PUF, 2007.

La raison, le langage et les normes. Paris: PUF, 1998a.

Língua e hiperlíngua. Tradução de Eduardo Guimarães. Línguas e instrumentos linguísticos, Campinas, v.1, p.17-30, jan./jun. 1998b.

. A revolução tecnológica da gramática. Tradução de Eni Orlandi. Campinas: Ed. da Unicamp, 1992.

Histoire des sciences et entropie des systèmes scientifiques. Les horizons de rétrospection. In: SCHIMITTER, P. (Ed.). Geschichte der sprachtheorie 1: zur theorie und methode der geschichtsschreibung der lingistik. Tübigen: Gunter Narr, 1987. p.20-42.

BARROS, J. de. Grammatica da lingua portuguesa. Dialogo em louvor da nossa linguagem. Olyssipone: Lodouicum Rotorigiu[m], 1540.

CUNHA, C.; CINTRA, L. Nova gramática do português contemporâneo. Rio de Janeiro: Nova Fronteira, 1985. 
FONSECA, P. J. da. Rudimentos da grammatica portugueza: commodos á instrucção da mocidade, e confirmados com selectos exemplos de bons Autores. Lisboa: Officina de Simão Thaddeo Ferreira, 1799.

KEIL, H. Grammatici latini. Hildesheim: Georg Olms, 1961.

LEÃO, D. N. de. Origem da lingoa portuguesa. Lisboa: Crasbeeck, 1606.

. Orthographia da lingoa portuguesa: obra vtil \& necessaria assi pera bem screuer a lingoa Hespanhol como a Latina \& quaesquer outras que da Latina teem origem. Item hum tractado dos pontos das clausulas. Lisboa: Ioão de Barreira, 1576.

LEITE, M. O. O nascimento da gramática portuguesa - uso e norma. São Paulo: Humanitas, 2007.

LOBATO, R. Arte da grammatica da lingua portugueza. Lisboa: Regia Officina Typografica, 1770.

MELLO, F. M. de. Apologos dialogaes. Lisboa: Mathias Pereira da Silva \& João Antunes Pedroso, 1721.

OLIVEIRA, F. Grammatica da lingoagem portuguesa. Lisboa: Germão Galharde, 1536.

PEREIRA, B. Ars Grammaticæ pro Lingua Lusitana addiscenda Latino Idiomate proponitur, in hoc libello, velut in quadam academiola divisa in quinque classes, instructas subselliis, recto ordine dispertitis, ut ab omnibus tum domesticis, tum exteris frequentari possint. Ac finem ponitur Ortographia, ars recte scribendi, ut sicut prior docet recte loqui, ita posterior doceat recte scribere linguam Lusitanam. In gratiam Italorum conjugationibus Lusitanis Italæ correspondent. Ludguni: Sumptibus Laurentii Anisson, 1672.

- Regras geraes breves e comprehensivas da melhor orthographia com que se podem evitar erros no escrever da lingua latina, e portugueza. Lisboa: Domingos Carneiro, 1666.

SOUZA, M. F. Historia del reyno de Portugal. Bruxelas: Francisco Foppens, 1730. 1678. . Europa portuguesa. 2. ed. il. e aum. Lisboa:Antonio Craesbeck de Mello, Epitome de las historias portuguesas. Madrid: Francisco Martinez, 1628.

VASCONCELOS, J. L. de. Esquisse d'une dialectologie portugaise. 3. ed. Lisboa: Instituto Nacional de Investigação Científica, 1987.

VERA, A. F. de. Orthographia ou modo para escrever certo na lingua portuguesa. Lisboa: Mathias Rodriguez, 1631. 


\section{BIBLIOGRAFIA CONSULTADA}

AUROUX, S. A hiperlíngua e a externalidade da referência. In: ORLANDI, E. P. (Org.). Gestos de leitura - da história no discurso. Campinas: Ed. da Unicamp, 1994. p.241-252.

Recebido em setembro de 2010.

Aprovado em janeiro de 2011. 